\title{
Characterization of the performance of brazilian adolescents in the Pitch Pattern Sequence (PPS) test developed by Auditec $\mathbb{R}$
}

Taina Maiza Bilinski Nardez ${ }^{1,2}$ https://orcid.org/0000-0002-4907-5893

Laura Mochiatti Guijo' https://orcid.org/0000-0003-2351-1105

Priscila de Araújo Lucas ${ }^{2}$ https://orcid.org/0000-0002-8653-6441

Ana Cláudia Vieira Cardoso' https://orcid.org/0000-0001-6808-419X

Universidade Estadual Paulista "Júlio de Mesquita Filho" - UNESP, Programa de Pós-graduação em Fonoaudiologia, Marília, São Paulo, Brasil.

Centro Universitário de Várzea Grande UNIVAG, Várzea Grande, Mato Grosso, Brasil.

A study carried out in the SpeechLanguage Pathology and Audiology

Course, Universidade Estadual Paulista "Júlio de Mesquita Filho" - UNESP -

Marilia, São Paulo, Brazil.

Conflict of interests: Nonexistent

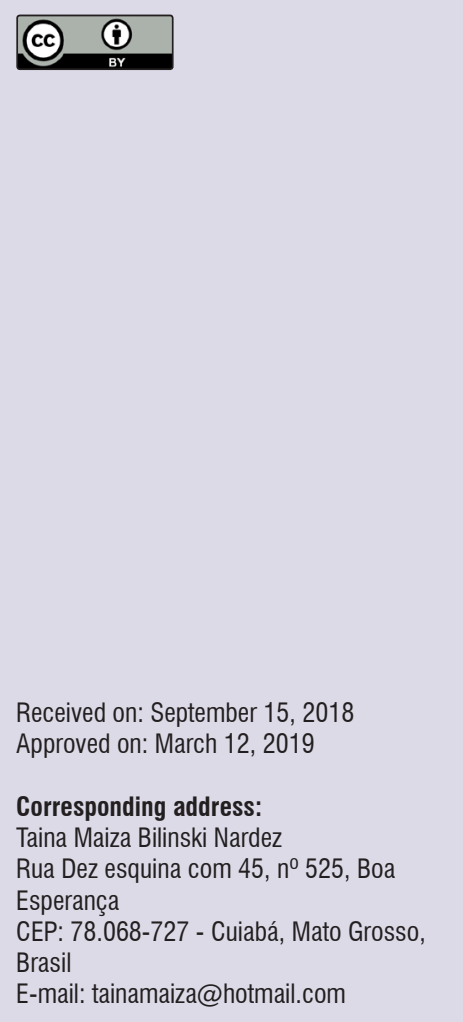

\section{ABSTRACT}

Purpose: to characterize the performance of Brazilian adolescents in the Pitch Pattern Sequence (PPS) test and compare the results with Auditec ${ }^{\circledR}$ normative values.

Methods: 26 adolescents enrolled in elementary or secondary education, of both sexes, and between 12 and 18 years, participated in the study. The inclusion criteria adopted were: a) no alterations in the visual inspection of the external acoustic meatus; b) hearing thresholds within the normal range for both ears, that is, values equal to or lower than $25 \mathrm{dBHL}$; $\mathrm{C}$ ) bilateral type "A" tympanometric curve, d) presence of acoustic reflex, contralateral mode, in the frequencies of 500,1000 and $2000 \mathrm{~Hz}$, in both ears, typical auditory behavior according to the Scale of Auditory Behaviors (SAB) or greater than 46 points. For adolescents, who met the inclusion criteria, the PPS (Auditec ${ }^{\circledR}$ version) was applied, binaurally, at 50dBSL. The findings were analyzed in a descriptive and inferential manner.

Results: statistical analysis showed significance only for the comparison of the mean value of $88.10 \%$, a result obtained in the PPS performed by Brazilians, when compared to the normative value (included) suggested by Auditec ${ }^{\circledR}$, in which the mean was $96 \%$.

Conclusion: the findings of this study demonstrated that the values obtained in the PPS, Auditec ${ }^{\circledR}$ version, in the Brazilian population, were similar to those presented in the international literature.

Keywords: Hearing; Auditory Tests; Hearing Perception; Acoustic Stimulation 


\section{INTRODUCTION}

Auditory processing is fundamental for understanding the information that is received aurally, and for this process to occur properly, the set of abilities that constitute this processing must be intact.

For the auditory information to be processed, it is necessary that the auditory abilities involved in this process be integrated, such as: sound detection and localization, speech recognition, figure-ground for verbal and non-verbal sounds, auditory closure synthesis ability, simple temporal ordering, complex temporal ordering, temporal pattern recognition, and the ability to discriminate sounds that includes temporal resolution, frequency and duration ${ }^{1,2}$.

Among these abilities, it is important to note that temporal processing is afundamental component for most auditory abilities. This process involves the concept of time, as well as other information about things, places and events that surround us, since it refers to the competence to process the sensorial aspects that vary with the period of occurrence, allowing the speech understanding and also reading ${ }^{3-5}$.

The discrimination of temporal order changes in sound waves demonstrates the adequate functioning of this process, which is indispensable for the perception of environmental sound patterns, called non-verbal sounds, and of speech, known as verbal sounds, since the acoustic temporal order of the elements is necessary for the understanding of the messages in the daily life ${ }^{6}$.

The temporal processing is not restricted to the perception of intervals between the stimuli, but it is also related to the short-term auditory memory, responsible for storing recent information for a short period of time $^{7,8}$ and it includes temporal resolution, temporal integration, temporal masking and temporal ordering abilities ${ }^{9}$.

The temporal ordering ability, or sequencing ability, refers to the processing of two or more auditory stimuli as a function of their order of occurrence over time. This ability has been widely investigated due to its importance in speech perception ${ }^{10}$.

Individuals with deficits in temporal abilities may have difficulty in perceiving changes in the acoustic stimuli that occur in a minimum time interval, causing them to present difficulties in the discrimination and phonological processing of sounds and, consequently, in the acquisition and development of the phonological system $^{11,12}$.
In the compiled literature three versions of the pitch pattern sequence test (PPS) and the duration pattern sequence test (DPS) were found, which are commercially available for evaluating the temporal ordering ability (Musiek, Auditec $\AA$, and Taborga-Lizarro).

Musiek developed and validated several clinical tests widely used, including PPS and DPS ${ }^{13}$. In 1998, Corazza applied the PPS and DPS, Musiek version, in a population of Brazilian normal hearing young adults, and established as a reference criterion, for normal range, a percentage of correctness greater than or equal to $76 \%$ for PPS and, $83 \%$ for DPS ${ }^{14}$.

Brazilian researchers applied the PPS and DPS, Musiek version, in a population of children and adolescents aged 7 to 16 years and verified a great variability in the PPS score in children under 12 years, thus the researchers suggested the application of this test from this age. In the group of participants aged $16 y e a r s$, the mean performance was $75.3 \%$ for the right ear and $72.5 \%$ for the left ear ${ }^{15}$.

This same PPS version was applied in a population of Brazilian elderly individuals who hadhearing thresholds within the normal range and verified that these individuals presented a mean percentage of correct answers of $49.2 \%{ }^{16}$.

Taborga-Lizarro (1999) elaborated a PPS version with melodic stimuli produced by a transverse flute. This version consists of musical tones of low $(440 \mathrm{~Hz})$ and highfrequency $(493 \mathrm{~Hz})$, with fixed duration and, are presented 10 sequences of three stimuli and 10 sequences of four stimuli. The author suggests that this test be applied in children from nine years of age, and the normality range adopted for the sequence of three melodic sounds is $70 \%$ and for the sequence of four sounds is $60 \%{ }^{17}$.

The temporal ordering ability can also be evaluated through another version developed by Auditec ${ }^{\circledR}{ }^{18}$. This instrument was standardized for the American population, and established, as a normality criterion $90 \%$ of correct answers for children aged 10 years or more. A Brazilian researcher applied the children's version of this instrument to evaluate the temporal ordering ability in children between 7 and 11 years old and observed an improvement in PPS scores in both ears with increasing age ${ }^{19}$.

Although audiologists use these tests in their clinical routine, a standardization of the normative values of the tests developed by Auditec ${ }^{\circledR}$ has not yet been performed for the Brazilian population. It can be noted 
that in the literature, at the national level, the area of neuro-audiological research has used the North American normality pattern as a normality criterion when applying the Auditec ${ }^{\circledR}$ version in Brazilian individuals. Therefore, the hypothesis of this study is that populations with different socio-cultural levels may present divergent performances in PPS.

Based on the above considerations, the present study aimed to characterize the performance of Brazilian adolescents in the Pitch Pattern Sequence (PPS) Test and to compare the results with the normative values of Auditec ${ }^{\circledR}$.

\section{METHODS}

This is an observational, cross-sectional and prospective study, based on a convenience sample, approved by the Research Ethics Committee of the Faculty of Philosophy and Sciences of UNESP (Faculdade de Filosofia e Ciências da UNESP) Marilia, under number 2.179.621. The adolescents who consisted of the sample were at the study site in order to perform the basic audiological assessment or admission examination and were subsequently invited to perform the central auditory processing evaluation. All participants in this study were invited to sign the Informed Consent Form (ICF) or the Informed Assent (IA).

The data collection of this study was performed in a private hospital, located in the city of Cuiabá, Mato Grosso. The sample was initially consisted of 30 adolescents enrolled in primary or secondary education, of both sexes, in the age range 12 and 18 years old.

In this study, the following inclusion criteria were adopted: a) absence of alterations in visual inspection of the external acoustic meatus; $b$ ) hearing thresholds within normal patterns in both ears; c) Bilateral type " $A$ " tympanometric curve and d) presence of contralateral acoustic reflex in the 500, 1000 and $2000 \mathrm{~Hz}$ frequencies in both ears and typical auditory behavior measured through SAB (score equal to or greater than 46 points).
Of the 30 adolescents, four were excluded because they did not meet the established inclusion criteria, that is, they did not reach a score equal to or greater than 46 points in the SAB. Thus, the sample of the present study consisted of 26 adolescents.

In order to verify if the adolescents met the established inclusion criteria, the following procedures were performed: visual inspection of the external auditory meatus, pure tone audiometry and tympanometry. The Visual inspection of the external auditory meatus was performed with the use of Mikatos otoscope. The pure tone audiometry was performed in an acoustic booth, using the AD 229-e audiometer (ANSI standard 3.6-1989 and S3.43- 1992) with a TDH-39 handset. The hearing thresholds were obtained by air conduction in the sound frequencies from 250 to $8000 \mathrm{~Hz}$. As a normality criterion was considered the quadritonal average equal to or less than $25 \mathrm{~dB}^{20}$.

In tympanometry, the AZ-26 tympanometer was used, with a probe tone of $226 \mathrm{~Hz}$. The tympanometry was performed in order to verify the mobility of the tympano-ossicular system. The normality criterion adopted was bilateral type A tympanometric curve, based on the classification proposed by JERGER ${ }^{21}$. The acoustic reflexes, contralateral mode, were tested in the frequencies of $500,1000,2000$ and $4000 \mathrm{~Hz}$. For the analysis, the presence of contralateral acoustic reflexes in the frequencies of 500,1000 and $2000 \mathrm{~Hz}$ was adopted as normal. The analysis the frequency of 4000 $\mathrm{Hz}$ was excluded due to the fact that individuals with hearing within normal patterns present higher acoustic reflex thresholds at this frequency as a consequence of rapid adaptation ${ }^{22}$

The Scale of Auditory Behaviors (SAB) was applied with parents in order to investigate whether adolescents presented typical auditory behavior, that is, scores equal to or greater than 46 points (Figure 1).

The characterization of the participants that corresponded to the inclusion criteria of the study and were tested with the Pitch Pattern Sequence (PPS) Test Auditec ${ }^{\circledR}$ adult version can be found in Table 1 . 
Name:

Date of birth: ___ _________ Schooling:

Signature of the subject or responsible:

Date:

\begin{tabular}{|c|c|c|c|c|c|}
\hline Behavior items & Frequent & Almost always & Sometimes & Sporadically & Never \\
\hline $\begin{array}{l}\text { 1. Difficulty listening or understanding in noisy } \\
\text { environment }\end{array}$ & 1 & 2 & 3 & 4 & 5 \\
\hline $\begin{array}{l}\text { 2. Does not understand well when someone } \\
\text { speaks fast or "muffled" }\end{array}$ & 1 & 2 & 3 & 4 & 5 \\
\hline 3. Difficulty following oral instructions & 1 & 2 & 3 & 4 & 5 \\
\hline $\begin{array}{l}\text { 4. Difficulty identifying and discriminating } \\
\text { speech sounds }\end{array}$ & 1 & 2 & 3 & 4 & 5 \\
\hline $\begin{array}{l}\text { 5. Inconsistency of response to auditory } \\
\text { information }\end{array}$ & 1 & 2 & 3 & 4 & 5 \\
\hline 6. Poor reading ability & 1 & 2 & 3 & 4 & 5 \\
\hline 7. Ask to repeat things & 1 & 2 & 3 & 4 & 5 \\
\hline 8. Easily distracted & 1 & 2 & 3 & 4 & 5 \\
\hline 9. Academic or learning difficulties & 1 & 2 & 3 & 4 & 5 \\
\hline 10. Short Attention Period & 1 & 2 & 3 & 4 & 5 \\
\hline 11. Dream awake, seem inattentive & 1 & 2 & 3 & 4 & 5 \\
\hline 12. Disorganized & 1 & 2 & 3 & 4 & 5 \\
\hline
\end{tabular}

Source: Nunes; Pereira and Carvalho (2013).

Figure 1. Scale of Auditory Behaviors (SAB).

The Auditec ${ }^{\circledR}$ adult version evaluates the temporal ordering ability and consists in the presentation of 30 three-tone sequences that differ in frequency: 1430 $\mathrm{Hz}$ for the high frequencies $(\mathrm{H})$ and $880 \mathrm{~Hz}$ for the low frequencies $(\mathrm{L})$. The adult version is applied from 9 years of age, the stimulus has a duration of 200 milliseconds (ms) with an interstimulus interval of 7 seconds between each sequence presented. The test has six possibilities of combination, these being: $(\mathrm{HHL}),(\mathrm{HLH})$, (HLL), (LHH), (LHL) and (HHL). The normality pattern established by Auditec ${ }^{\circledR}$ for the PPS is a percentage of correct answers equal to or greater than $88 \%$.

Prior to the beginning of the test, a training was conducted in order to ensure the understanding of the task to be performed by the participants. The test was applied in a binaural mode at an intensity of 50 $\mathrm{dB} \mathrm{HL}$ above the tritonal average. The participants were instructed to name the stimuli in the order of their presentation.

The findings were analyzed in a descriptive and inferential manner. In the descriptive analysis, the performance of Brazilian adolescentsin PPS was characterized through measures such as mean, median and standard deviation. In the inferential analysis, the non-parametric Student One Sample T-test was applied to compare the performance of Brazilian adolescents to the normative standard proposed by Auditec $\AA$. A significance level of $a \leq 0.01$ and a confidence interval of $99 \%$ were established. 
Table 1. Characterization of study participants regarding age and sex

\begin{tabular}{ccc}
\hline Participants & Age & Sex \\
\hline 1 & 12 & $\mathrm{~F}$ \\
2 & 15 & $\mathrm{~F}$ \\
3 & 16 & $\mathrm{~F}$ \\
4 & 17 & $\mathrm{~F}$ \\
5 & 16 & $\mathrm{M}$ \\
6 & 16 & $\mathrm{M}$ \\
7 & 16 & $\mathrm{~F}$ \\
8 & 16 & $\mathrm{~F}$ \\
9 & 13 & $\mathrm{~F}$ \\
10 & 12 & $\mathrm{M}$ \\
11 & 14 & $\mathrm{M}$ \\
12 & 13 & $\mathrm{~F}$ \\
13 & 12 & $\mathrm{M}$ \\
14 & 14 & $\mathrm{M}$ \\
15 & 16 & $\mathrm{M}$ \\
16 & 14 & $\mathrm{~F}$ \\
17 & 17 & $\mathrm{~F}$ \\
18 & 17 & $\mathrm{M}$ \\
19 & 18 & $\mathrm{~F}$ \\
20 & 15 & $\mathrm{M}$ \\
21 & 17 & $\mathrm{~F}$ \\
22 & 12 & $\mathrm{M}$ \\
23 & 14 & $\mathrm{M}$ \\
24 & 12 & $\mathrm{M}$ \\
25 & 12 & $\mathrm{M}$ \\
26 & 14 & $\mathrm{M}$ \\
Mean & 14.61 & - \\
Median & 1.90 & - \\
\hline
\end{tabular}

Legend: PPS = Pitch Pattern Sequence Test, SD = Standard Deviation, $\mathrm{F}=$ Female, $\mathrm{M}=$ Male.

\section{RESULTS}

Results of this research were organized in order to analyze the performance of Brazilian adolescents in the Pitch Pattern Sequence Test Auditec ${ }^{\circledR}$ version. The descriptive data about the characterization of study participants regarding the score obtained in the PPS are shown in Table 2.

When comparing the mean values of PPS of the Brazilian adolescents to the normative values proposed by Auditec $\AA$ version, it was noticed that both values were similar. Data regarding the comparison of the
Auditec $\circledast$ normative values with the values obtained by Brazilian participants in the PPS, Auditec ${ }^{\circledR}$ version, are also presented in Table 2.

When analyzing the data in Table 2 , it was possible to observe that the statistical analysis showed significance only for the comparison of the mean value of 88.10 , result obtained in the PPS performed by Brazilians, when it was compared to the normative value regarding the inversions suggested by Auditec ${ }^{\circledR}$, in which the mean is 96.0 . 
Table 2. Characterization of the adolescents' score and comparison of values of the Pitch Pattern Sequence (PPS) of Brazilian adolescents with normative values of Auditec ${ }^{\circledR}$, and score obtained in the Pitch Pattern Sequence (PPS) Test

\begin{tabular}{|c|c|c|}
\hline Participants & PPS score $\%$ & Reference standard in the PPS Auditec ${ }^{\circledR}$ version \\
\hline 1 & 96.66 & \\
\hline 2 & 96.66 & Adults (no inversions): 90\% \\
\hline 3 & 73.33 & Adults (with inversions): $96 \%$ \\
\hline 4 & 96.66 & \\
\hline 5 & 90.00 & \\
\hline 6 & 90.00 & \\
\hline 7 & 90.00 & \\
\hline 8 & 93.33 & \\
\hline 9 & 70.00 & \\
\hline 10 & 90.00 & \\
\hline 11 & 96.66 & \\
\hline 12 & 76.66 & \\
\hline 13 & 96.66 & \\
\hline 14 & 73.33 & \\
\hline 15 & 100.00 & \\
\hline 16 & 96.66 & \\
\hline 17 & 90.00 & \\
\hline 18 & 90.00 & \\
\hline 19 & 76.66 & \\
\hline 20 & 93.33 & \\
\hline 21 & 90.00 & \\
\hline 22 & 60.00 & \\
\hline 23 & 90.00 & \\
\hline 24 & 96.66 & \\
\hline 25 & 100.00 & \\
\hline 26 & 70.00 & \\
\hline Mean & 88.10 & \\
\hline SD & 11.10 & \\
\hline Median & 90.00 & \\
\hline $\mathrm{N}$ & 26 & \\
\hline P-value (no inversions) & 0.389 & \\
\hline P-value (with inversions) & $0.001^{*}$ & \\
\hline
\end{tabular}

Legend: $\mathrm{SD}=$ Standard Deviation, $\mathrm{N}=$ number of participants, PPS = Pitch Pattern Sequence Test

$\mathrm{P}$-value for the nonparametric Student $\mathrm{One}$ Sample T-test - significant values are in bold and with an asterisk.

\section{DISCUSSION}

Currently, researchers have discussed about the topic central auditory processing, auditory training therapy, and the impact of the disordered auditory abilities on the individual23.

The temporal processing is an essential component of most central auditory processing abilities. Thus, the characterization of performance of the Brazilian population for the temporal ordering ability and the obtention of normative values are greatly relevant for the clinical and diagnostic process.
In the compiled literature, in one of the studies, the researchers applied the PPS and DPS (Auditec ${ }^{\circledR}$ children's version) monoaurally in 229 participants aged between 7 and 11 years, enrolled in public schools. Analysis of the results showed that for the 10-year age group the mean number of correct answers to the PPS was $75.9 \%$ and, for 11 -year age group was $83 \%$ of correct answers ${ }^{24}$. The author concluded that with increasing age there is an improvement in the mean number of correct answers in this test.

In the present study, the evaluated population was adolescents between 12 and 18 years of age and, 
the application mode of the PPS was binaural. When analyzing the results, it was possible to verify that the mean values obtained $(88.10 \%)$ were in consonance with the values proposed by Auditec ${ }^{\circledR}$ (variation between 88 and 100\%), but it should be noted that there was statistical difference between the mean values of this study when they were compared to the Auditec ${ }^{\circledR}$ normative value regarding the inversions. Lower mean values than those found in this study were described by researchers in a previous study ${ }^{25}$, but they suggest that adolescents obtain better scores in relation to children in the age group from 7 to 11 years. However, one aspect that cannot be ignored is the application mode of the test, because in the previous study the researcher applied the test monoaurally and in this study, the test was applied binaurally.

In another study whose objective was to standardize PPS and DPS, the researcher evaluated 80 young adults of both sexes, with no evidence of auditory disorders and musical experience, who attended or had completed higher education. The PPS and DPS (MUSIEK version - 1997) were applied, in a monaural mode, at two levels of intensity, $50 \mathrm{~dB} \mathrm{HL}$ and $20 \mathrm{~dB} \mathrm{HL}$ above the tritonal average.Data analysis showed that there was no influence of the variable ear (right and left) and the level of intensity at which the test was applied ( $50 \mathrm{~dB} \mathrm{HL}$ and $20 \mathrm{~dB} \mathrm{HL}$ ) in the performance of the participants. However, it was observed that the male participants presented higher performance than the female ones. Regarding the index of correct answers, in percentages, there was a variation range between $76 \%$ and $100 \%$ of correct answers for PPS and between $83 \%$ and $100 \%$ of correct answers for DPS ${ }^{14}$.

The results of the previously described study showed a range of correct answers from $76 \%$ to $100 \%$, which is similar to the mean of $88.10 \%$ of correct answersobtained in the participants of this study. However, it should be noted that the version applied (Auditec X Musiek) (monoaural X binaural) and the age of the participants evaluated are divergent.

Researchers applied the PPS and DPS (MUSIEK version - 1994), in a monoaural mode, to verify the performance of children and young individuals in these tests. A total of 148 Brazilian individuals aged between 7 to 16 years were evaluated and, for the analysis, these were divided by age group.This version is standardized for individuals from 12 years of age, with a mean of correct answers of $78 \%$ for both ears. The comparison of scores showed that some groups achieved averages better than the others.However, the 15-year age group presented the highest score for both ears, reaching a mean of $78.6 \%$ for the right ear and $72.6 \%$ for the left ear, in which these values were similar to the standardized values in the international literature. The comparison of performance in the various age groups showed that there was a considerable variation in the scores of children from 7 to 11 years, which did not occur from the age of 12 years. Then, it was suggested that these tests be applied from 11 years of age ${ }^{15}$.

In the present study, it was opted to evaluate the adolescent population due to the lack of research in the audiological field aimed at investigating the central auditory processing disorders in this population nationally, and also due to the findings gathered in the literature ${ }^{15}$ that recommended the application of PPS from 11 years of age.

The temporal ordering ability was evaluated through different test versions, and the authors verified the specificity of each test and compared the result with the degree of ease/difficulty reported by the participants. Thirty-three individuals, of both sexes, with an average age of 18 years, presenting hearing thresholds within the normal range were evaluated. To evaluate the temporal ordering ability, PPS and DPS were applied in the Taborga-Lizarro, Musiek and Auditec ${ }^{\circledR}$ versions. The analysis of the results showed that there was a greater number of subjects who reached compatible values with normality in the Auditec $\AA$ and TaborgaLizarro versions, both for the PPS and the DPS, and the comparison of the results of subjects with and without alteration showed significant difference in these two versions. The same did not occur with the Musiek version, in which the number of subjects with normal results was very close to the number of subjects with altered results, and there was no statistical difference in any of the tests, PPS and DPS. In relation to the comparison of the results with the degree of ease/ difficulty reported by the subjects, it was observed that the test version considered more difficult was the Musiek version and, as the analysis of the test specificity, the authors demonstrated that the best results were for the Auditec ${ }^{\circledR}$ version ${ }^{25}$.

Thus, it can be inferred that the applicability of the PPS Auditec ${ }^{\circledR}$ version may be the best choice for the evaluation of the temporal ordering ability, since the individuals evaluated in the previously mentioned study reported greater ease in answering to this test version when compared to the other versions, hence, obtaining a better response pattern. 
Findings of this study demonstrated that the mean values obtained in the application of PPS in Brazilian adolescents were similar to those referenced in the international literature for the North American population. From this, it should be mentioned that although North American individuals show socio-cultural characteristics distinct from the Brazilian population, the temporal perception patterns of sounds are similar.

Future research is needed to foster discussions and to verify if aspects such as intensity and application mode to test temporal auditory processing abilities, monaurally or binaurally, are variables that can influence the results of the test in the same population. A limiting factor of this study was the number of individuals that composed the sample evaluated, so it is suggested that future research be conducted regarding a larger number of participants.

\section{CONCLUSION}

The results showed that in the studied population, the PPS values were similar to those presented in the international literature that used the version developed by Auditec ${ }^{\circledR}$. Therefore, the normative values obtained in this study may be suggestive for the use of this test when evaluating temporal ordering abilities in Brazilian adolescents. However, future studies aimed at the test standardization for the evaluation of temporal auditory abilities will be of great scientific and clinical relevance.

\section{REFERENCES}

1. Pereira LD. Sistema auditivo e desenvolvimento das habilidades auditivas. In: Ferreira LP, Befi-Lopes DM, Limonge SCO (Orgs). Tratado de Fonoaudiologia. São Paulo: Roca, 2004. P.547-52.

2. AMERICAN SPEECH-LANGUAGE-HEARING ASSOCIATION (ASHA) (Central) Auditory processing disorders. Technical report. 2005. Disponível em: http://www.asha.org/policy. Acessado em: 08 de fevereiro de 2018.

3. Shinn JB. Temporal processing: the basics. Hear J. 2003;56:52.

4. Banai K, Kraus N. Neurobiology of (central) auditory processing disorder and language-based learning disability. Handbook of (central) Auditory neuroscience an diagnosis. San Diego (CA): Plural Publishing; 2007;1. P. 89-116.

5. Pina VMG. Processamento temporal: sua importância para a aprendizagem da leitura. Construção Psicopedagógica. 2012;20(20):20-34.
6. Musiek FE, Shinn JB, Bamiou DE, Baran JA, Zaida E. GIN (Gaps-In-Noise) test performance in subjects with confirmed central auditory nervous system involvement. Ear Hear. 2005;26(6):608-18.

7. Rawool VW. Temporal processing in the auditory system. In: Geffner D, Ross-Swain D (eds). Auditory processing disorders: assessment, management, and treatment. San Diego (CA): Plural Publishing; 2007. P.117-37.

8. Nunes CL. Processamento auditivo: conhecer, avaliar e intervir. 1. ed. Lisboa: Papa-Letras. 2015.

9. Shinn J. Temporal processing and temporal patterning tests. In: Musiek F, Chermak G (orgs). Handbook of (Central) Audiotory Processing Disorder. Auditory Neuroscience and Diagnosis. San Diego (CA): Plural Publishing; 2007. P.231-56.

10. Pichora-Fuller MK, Souza PE. Effects of aging on auditory processing of speech. Int $\mathrm{J}$ Audiol. 2003;42(2):11-6.

11. Garcia VL, Campos DBKP, Padovani CR. Associação entre a avaliação de habilidades de consciência fonológica e processamento auditivo em crianças com e sem distúrbio de aprendizagem. Fono Atual. 2005;8(31):4-11.

12. Fortes $A B$, Pereira LD, Azevedo MF. Resolução temporal: análise em pré-escolares nascidos a termo e pré-termo. Pró-Fono R. Atual. Cient. 2007;19(1):87-96.

13. Musiek FE, Baran JA, Pinheiro ML. Duration pattern recognition in normal subjects and patients with cerebral and cochlear lesions. Audiology. 1990;29(6):304-13.

14. Corazza MCA. Avaliação do processamento auditivo central em adultos: teste de padrões tonais auditivos de frequência e teste de padrões tonais auditivos de duração [tese]. São Paulo (SP): Universidade Federal de São Paulo; 1998.

15. Schochat E, Rabelo CM, Sanfins MD. Processamento auditivo central: testes tonais de padrão de frequência e de duração em indivíduos normais de 7 a 16 anos de idade. Pró-Fono R. Atual. Cient. 2000;12(2):1-7.

16. Parra VM, lório MCM, Mizahi MM, Baraldi GS.Testes de padrão de frequência e duração em idosos com sensibilidade auditiva normal. Rev Bras Otorrinolaringol. 2004;70(4):517-23.

17. Pereira LD, Schochat E. Testes auditivos comportamentais para avaliação do processamento auditivo central. São Paulo: Pró Fono, 2011. 
18. Auditec. Evaluation manual of pitch pattern sequence and duration pattern sequence. Missouri; 1997.

19. Balen SA. Reconhecimento de padrões auditivos de frequência e duração: desempenho de crianças escolares de 7 a 11 anos [Tese]. São Paulo (SP): instituto de Psicologia, Universidade de São Paulo; 2001.

20. Organização Mundial de Saúde. Grades of Hearing Impairment: 2014; Disponível em: http://www.who. int/pbd/deafness/hearing_ impairment_grades/en/. Acesso em: 08/02/2018.

21. Jerger J. Clinical experience with impedance audiometry. Arch Otolaryng. 1970;92(4):311-24.

22. Gelfand SA. Essentials of audiology. ( $3^{\text {rd }}$ ed.). New York (NY): Thieme Medical Publishers; 2009.
23. Padilla J, Morlet T, Nagao K, Crum R, Greenwood LA, Loson J et al. Speech perception capabilities in children a few years after initial diagnosis of auditory processing disorder. Acoustical Society of America. 2015;25(2):1-6.

24. Balen SA. Processamento auditivo central: aspectos temporais da audição e percepção acústica da fala [dissertação]. São Paulo (SP): Pontifícia Universidade Católica de São Paulo; 1997.

25. Gois M, Biaggio EPV, Bruckmann M, Pelissari I, Bruno RS, Garcia MV. Temporal ordering ability and level of specificity at different pure tone tests. Audiol. Commun. Res. 2015;20(4):293-9. 